Journal of Animal and Veterinary Advances 10 (17): 2234-2239, 2011

ISSN: $1680-5593$

(C) Medwell Journals, 2011

\title{
Populations of Salmonella enteritidis in Orally Infected White Chinese Goose
}

\author{
${ }^{1}$ Guang-Zhi He, ${ }^{1}$ Yong Feng, ${ }^{1}$ Wei-Yi Tian, ${ }^{1}$ Ning Qian, ${ }^{2}$ Shu-Xuan Deng and ${ }^{1}$ Chuan-Wei An \\ ${ }^{1}$ Guiyang College of Traditional Chinese Medicine, 550002 Guiyang, Guizhou Province, China \\ ${ }^{2}$ Agricultural Office of Dalingshan Town, 523830 Dongguan, Guandong Province, China
}

\begin{abstract}
The objective of this study was to understand populations of Salmonella enteritidis (S. enteritidis) in the internal organs of geese after oral challenge. Researchers conducted serovar-specific Fluorescent Quantitative Real-Time PCR (FQ-PCR) for S. enteritidis to detect the genomic DNA of S. enteritidis in the blood and the internal organs including heart, liver, kidney, duodenum, jejunum, ileum, cecum, the bursa of fabricius, thymus, spleen and harderian gland from geese after oral challenge at different time points. To validate these results, the Indirect Fluorescent Antibody (IFA) technique was employed. The results showed that S. enteritidis was consistently detected in all the samples. Ileum and jejunum were positive at $8 \mathrm{~h}$ PI and the last organ to show a positive result was the thymus at $36 \mathrm{~h}$ PI. The copy numbers of $S$. enteritidis DNA in each tissue reached a peak at $24 \mathrm{~h}$ and 2 nd day PI with the blood, jejunum, ileum, liver and spleen containing higher concentrations than other tissues. However, the number of bacteria started decreasing by 2-3 days and by 6 days, the concentration of $S$. enteritidis DNA was below the detection limits of the FQ-PCR assay except the spleen. The IFA results were similar to those of the FQ-PCR. This study will help in understanding the pathogenesis of $S$. enteritidis infection in vivo.
\end{abstract}

Key words: Salmonella enteritidis, internal organs, distribution, goose, detection, tissues, China

\section{INTRODUCTION}

The Chinese goose is a breed of domesticated goose descended from the wild Swan goose. Chinese geese differ from the wild birds in much larger size (up to $5-10 \mathrm{~kg}$ in males, 4-9 $\mathrm{kg}$ in females) and in having an often strongly developed basal knob on the upper side of the bill. The knob at the top of the beak is more prominent on males than females. By 6-8 weeks of age, the knob is already pronounced enough that it can be used for mating. Chinese geese are a close cousin of the African goose, a heavier breed also descended from the Swan goose. In Gui Zhou, China, the consumption of goose products is high and the number of $S$. enteritidis cases in humans has increased considerably in recent years. Further, this disease has had significant economic impacts on the poultry industry especially the egg industry (Gillespie et al., 2005). Due to the increased prevalence of S. enteritidis and its complex pathogenesis, it is important to understand the correlation between the levels of this bacterium in internal organs and the progression of the infection (Deng et al., 2008a), this has not been previously described in geese. Generally, little is known about the pathogenesis of $S$. enteritidis in geese after $S$. enteritidis infected (Takata et al., 2003). Up to day, the mechanisms by which $S$. enteritidis and other serotypes persist within the host and the reasons for the absence of immune clearance are not known. In a susceptible host, $S$. enteritidis replicates primarily in the mucosa of the digestive tract after oral challenge and then spreads to the spleen, liver and various other organs and tissues after oral challenge (Dibb-Fuller et al., 1999). The objectives of the present study were to determine the pathogenesis of a high-virulence strain of $S$. enteritidis (No. 50338; phage type 4) in geese by a time-course study using a quantitative TaqMan assay (Deng et al., 2008b); researchers believe that this analysis will help provide valuable insights into the etiology of $S$. enteritidis infections.

\section{MATERIALS AND METHODS}

Bacterial strains: A high-virulence strain of S. enteritidis (phage type 4; No.: 50338) was purchased from the National Center for Medical Culture Collection.

Experimental animals and samples: Three months old white Chinese geese free from S. enteritidis infection were used in the study. Prior to challenge with $S$. enteritidis, all geese were found to be negative for $S$. enteritidis-specific antibodies and $S$. enteritidis specific antigens by an enzyme-linked immunosorbent assay and PCR, respectively (Deng et al., 2008a; Gast and Beard, 1990). The geese were maintained in isolation units in a biosecure animal building. In brief, $S$. enteritidis cells were grown overnight in a Luria-Bertani broth. The cells were cultured overnight and then the presumptive live number of $S$. enteritidis cells was determined by the spread plate

Corresponding Author: Yong Feng, Guiyang College of Traditional Chinese Medicine, 550002 Guiyang, Guizhou Province, China 
method. Thereafter, a group of 52 geese were orally infected with a high-virulence $S$. enteritidis strain (No. 50338; phage type 4). Animal experiments were reviewed by an Institutional Animal Care and Use Committee (IACUC) for humane use of animal for experimental purposes. Each goose was orally infected with a S. enteritidis strain (No. 50338), at $4.0 \times 10^{5}$ cells goose ${ }^{-1}$. Another group of 56 goose was treated with an equal volume of water and used as a control group. The blood, heart, liver, kidney, duodenum, jejunum, ileum, cecum, the bursa of fabricius, thymus, spleen and harderian gland were analyzed by a FQ-PCR assay at postinoculation times of $30 \mathrm{~min} ; 4,8,10,12,24,36$ and $60 \mathrm{~h}$ and $2,3,6,9$ and 12 days. At each time point, 4 geese were randomly selected from the infection and control groups and their tissue samples were collected and processed for further analyses. DNA from the tissue samples was performed as described previously (Deng et al., 2008b). Briefly, $0.5 \mathrm{~g}$ of the tissue sample was ground up using a tissue grinder in the $1.5 \mathrm{~mL}$ Eppendorf tube. The pellet was resuspended in $500 \mu \mathrm{L}$ TE buffer ( $\mathrm{pH} 8.0$ ) with $10 \mu \mathrm{L}$ Proteinase $\mathrm{K}$ $\left(30 \mathrm{~g} \mathrm{~L}^{-1}\right)$ and incubated at $37^{\circ} \mathrm{C}$ for $2 \mathrm{~h}$. A $0.5 \mathrm{~mL}$ blood sample was suspended in $500 \mu \mathrm{L}$ PBS directly. Finally with a conventional phenol/ chloroform/isoamyl alcohol method to extract the genomic DNA of $S$. enteritidis from tissue used $5 \mu \mathrm{L}$ aliquot of DNA template for FQ-PCR detection.

Quantitative real-time PCR assay for detection of S. enteritidis DNA: In the previous study, there have established a serovar specific real-time PCR assay (GenBank Accession No. AF370707.1), the limit of detection was 70 copies $^{-1}$ (Deng et al., 2008a). Brifely, a real-time PCR assay was carried out using a real-time PCR core kit (R-PCR Version 2.1, Takara, Japan) with an Icycler $\mathrm{iQ}^{\mathrm{TM}}$ real-time PCR detection system (Version 3.1, Bio-rad, USA) and was performed as described previously. PCR amplification was performed in a $25 \mu \mathrm{L}$ reaction mixture containing $0.6 \mu \mathrm{L}$ of each primer $\left(10 \mu \mathrm{mol} \mathrm{L}{ }^{-1}\right), 0.75 \mu \mathrm{L}$ deoxyribonucleotide triphosphates (dNTPs) (10 $\left.\mathrm{mmol} \mathrm{L}^{-1}\right), 1.25 \mathrm{U}$ Ex Taq DNA Polymerase (Takara Ex Taq Hot Start Version, Takara, Japan), $5 \mu \mathrm{L}$ of $5 \times$ PCR buffer (free $\left.\mathrm{Mg}^{2+}\right), 0.8 \mu \mathrm{L}$ TaqMan probe $(5 \mu \mathrm{mol}$ $\left.\mathrm{L}^{-1}\right), 0.5 \mu \mathrm{L} \mathrm{Mg}^{2+}\left(250 \mathrm{mmol} \mathrm{L}^{-1}\right)$ and $5 \mu \mathrm{L}$ templates. The reaction mixture was subsequently made up to a volume of $25 \mu \mathrm{L}$ with deionized water. Each PCR run consisted of a $5 \mathrm{~min}$ hot start at $95^{\circ} \mathrm{C}$ which activated the conjugated polymerase followed by 40 cycles consisting of $30 \mathrm{sec}$ of denaturation at $94^{\circ} \mathrm{C}, 30 \mathrm{sec}$ of annealing at $55^{\circ} \mathrm{C}$ and a fluorescent read step.

Differences between the FQ-PCR and IFA assay results: To validate the results, researchers simultaneously performed a quantitative bacteriological test to determine the bacterial burden in the corresponding tissues and compare these data with the PCR data. In the previous study, there was also established a specific method of IFA staining for $S$. enteritidis (Yan et al., 2008). At present, researchers relied on the IFA assay to study the distribution pattern and quantity of $S$. enteritidis in the internal organs of geese after oral challenge.

Statistical analysis: The PCR assay and data acquisition and analysis were performed using the iCycler iQ Optical system software (Version 3.1 ; Bio-Rad, USA). The number of target copies in the reaction was deduced from the threshold cycle values. The threshold cycle value corresponds to the fractional cycle number at which the fluorescence emission exceeds the standard deviation of the mean baseline emission by 15 -fold. Plasmid DNA containing the target amplicon was diluted to contain $7.0 \times 10^{2}-7.0 \times 10^{8}$ copies of the target DNA per test tube and used as the plasmid standard series. All samples were analyzed 3 times by the real-time PCR assay and concentrations of the target DNA detected were expressed as the mean $\log _{10}$ of the bacterial genome copy number per gram of tissue tested. The real-time PCR data were analyzed using Version 11 of the SPSS software. The comparison of means was performed using Duncan's multiple-range test. The $\mathrm{p}<0.05$ was considered statistically significant.

\section{RESULTS}

The distribution of $S$. enteritidis within the internal organs after oral challenge was determined by means of FQ-PCR over a 12 days period at intervals. The results showed that the jejunum and ileum tested positive for $S$. enteritidis at $8 \mathrm{~h}$ PI. Thereafter, $S$. enteritidis was consistently detected in all the samples at $12 \mathrm{~h}$ PI; the last organ to show a positive result was the thymus at $36 \mathrm{~h}$ PI. The copy numbers of $S$. enteritidis in each tissue reached a peak at $24 \mathrm{~h}$ and $2 \mathrm{nd}$ day PI.

The blood, spleen, liver, jejunum and ileum contained high concentrations of $S$. enteritidis whereas the kidney, Harderian gland, bursa of Fabricius and Thymus exhibited low concentrations. The numbers of bacteria decreased at 2nd and 3rd day. By 6 days, all the sample did not show positive results except the spleen. The internal organs of the geese in the control group did not show any positive results at any time point. The details are shown in Table 1.

The jejunum and ileum exhibited a positive $S$. enteritidis signal by IFA at $10 \mathrm{~h}$ PI. Thereafter, a positive signal was detected in all the samples at $36 \mathrm{~h}$ to 2 days; a stronger positive signal was observed in the spleen, jejunum, ileum and liver compared to the other organs. The positive $S$. enteritidis signal clearly decreased at $60 \mathrm{~h}$ PI and no positive results were detected in thymus. However, it was possible to detect a positive 
J. Anim. Vet. Adv., 10 (17): 2234-2239, 2011

Table 1: Kinetics of S. enteritidis DNA loads in geese orally infected with a high-virulence strain determined by quantitative real-time PCR

\begin{tabular}{lcccccccccccccc}
\hline Time & $30 \mathrm{~min}$ & $4 \mathrm{~h}$ & $8 \mathrm{~h}$ & $10 \mathrm{~h}$ & $12 \mathrm{~h}$ & $24 \mathrm{~h}$ & $36 \mathrm{~h}$ & 2 days & $60 \mathrm{~h}$ & 3 days & 6 days & 9 days & 12 days \\
\hline Heart & 0.0 & 0.0 & 0.0 & 0.0 & 2.8 & 3.3 & 4.3 & 5.3 & 4.4 & 2.7 & 0.0 & 0.0 & 0.0 \\
Liver & 0.0 & 0.0 & 0.0 & 0.0 & 2.6 & 4.1 & 4.8 & 6.5 & 4.1 & 3.3 & 0.0 & 0.0 & 0.0 \\
Kidney & 0.0 & 0.0 & 0.0 & 0.0 & 2.0 & 2.9 & 3.6 & 4.6 & 3.4 & 0.0 & 0.0 & 0.0 & 0.0 \\
Duodenum & 0.0 & 0.0 & 0.0 & 0.0 & 2.4 & 3.2 & 4.7 & 5.7 & 4.5 & 3.0 & 0.0 & 0.0 & 0.0 \\
Jejunum & 0.0 & 0.0 & 2.1 & 2.5 & 3.7 & 4.5 & 6.4 & 8.1 & 5.9 & 4.7 & 0.0 & 0.0 & 0.0 \\
Ileum & 0.0 & 0.0 & 2.3 & 2.7 & 3.6 & 4.5 & 6.3 & 7.9 & 6.3 & 4.2 & 0.0 & 0.0 & 0.0 \\
Cecum & 0.0 & 0.0 & 0.0 & 0.0 & 2.4 & 3.6 & 4.7 & 5.7 & 4.2 & 2.3 & 0.0 & 0.0 & 0.0 \\
BF & 0.0 & 0.0 & 0.0 & 0.0 & 0.0 & 1.9 & 2.5 & 2.9 & 1.8 & 0.0 & 0.0 & 0.0 & 0.0 \\
Thymus & 0.0 & 0.0 & 0.0 & 0.0 & 0.0 & 0.0 & 2.3 & 2.6 & 0.0 & 0.0 & 0.0 & 0.0 & 0.0 \\
Spleen & 0.0 & 0.0 & 0.0 & 2.1 & 2.6 & 3.9 & 5.3 & 7.2 & 6.4 & 3.4 & 2.9 & 2.3 & 1.9 \\
HD & 0.0 & 0.0 & 0.0 & 0.0 & 0.0 & 1.9 & 2.6 & 4.9 & 1.9 & 0.0 & 0.0 & 0.0 & 0.0 & \\
Blood & 0.0 & 0.0 & 0.0 & 0.0 & 1.9 & 3.1 & 5.2 & 6.9 & 4.8 & 3.6 & 0.0 & 0.0 & 0.0 \\
\hline
\end{tabular}

The unit: $\log _{10}$ copies $\mathrm{mL}^{-1}$ for blood and $1 \mathrm{~g}$ copies $\mathrm{g}^{-1}$ for others each time point represents the mean concentration of genomic DNA and is expressed as $\log _{10}$ of the bacterial genome copy numbe/g/mL of tissue tested obtained from 4 geese. Each sample was analyzed 3 times by the FQ-PCR assay. In this study, researchers get the mean from 12 tests for each sample and the 12 results were not different for each sample $(p>0.05)$; min $=\operatorname{minute}, \mathrm{h}=$ hour, $d=$ day, $\mathrm{BF}=$ Bursa of Fabricius, $\mathrm{HD}=$ Harderian gland
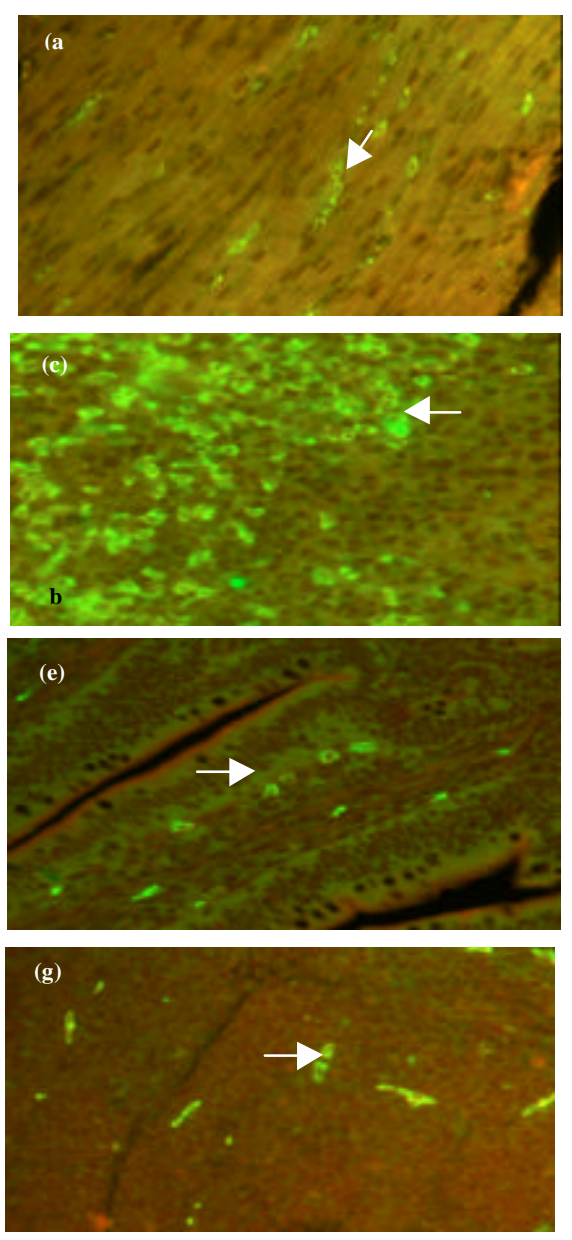
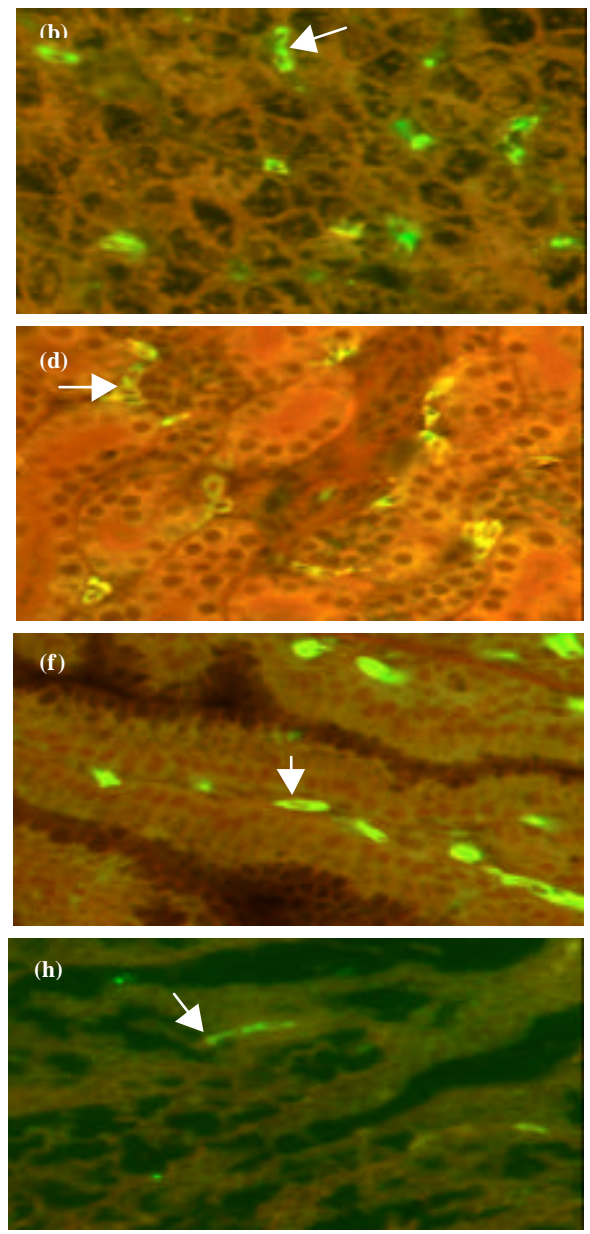

Fig. 1: An IFA staining assay was used to detect S. enteritidis in the infected-group samples at $36 \mathrm{~h}$ PI. Samples from infected-group showing positive result; images were acquired by using a $60 \times$ objective; $a=$ Heart, $b=$ Liver, $\mathrm{c}=$ Spleen, $\mathrm{d}=$ Kidney, $\mathrm{e}=$ Cecum, $\mathrm{f}=$ Harderian gland, $\mathrm{g}=$ Bursa of fabricius, $\mathrm{h}=$ Thymus

signal in the spleen at 6th day PI. Apparently, the results were similar to the results of FQ-PCR. Therefore, the
FQ-PCR assay was considered to be a more sensitive and accurate method for this study (Fig. 1). 


\section{DISCUSSION}

Many studies confirmed that the bursa of Fabricius, harderian gland and thymus have significant roles to play in the development of adaptive immunity (Cooper, 2002; Glick, 1995). It has also been determined that $\mathrm{M}$ cells are interspersed within the follicle-associated epithelium of each follicle which explains the movement of antigens from the lumen into the medulla of the follicle where immature B cells develop (Sayegh and Ratcliffe, 2000; Scott, 2004). Furthermore, it has been reported that the limited gene rearrangement of pre-bursal cells and the gene conversion events primarily produce antibody diversity in the bursal cells of poultry (Weill and Reynaud, 1987). In this study, the results showed that the $S$. enteritidis populations in the bursa of fabricius, harderian gland and thymus were much lower than that in the other organs sampled with copies of $S$. enteritidis being 10000-100000 times less than those in other regions. The possible reasons for this occurrence are described above.

Interestingly, $S$. enteritidis organisms have a higher tropism in the Harderian gland than in the thymus and bursa of fabricius with copies of $S$. enteritidis being 100 times more than those described pervious. It has been reported that the Harderian gland plays an important role in controlling mucosal immunity in chickens ( $\mathrm{Li}$ et al., 2004). IgA-positive lymphocytes migrate from the Harderian gland to the caecal tonsils; the route of lymphocyte migration from the Harderian gland to the intestine is not clear (Akaki et al., 1997). Moreover, it has been reported that significant $\operatorname{IgG}$ and $\operatorname{IgA}$ antibody responses were induced in both the serum and intestinal mucosa (Akaki et al., 1997). Previous studies suggested that lymphocytes in the bursa of fabricius differentiate into Ig-producing cells in the Harderian gland and immunization with liposomes stimulates the Harderian gland lymphocytes to produce IgA and IgG thereafter, lymphocytes in the caecal tonsil that may have migrated from the Harderian gland induce an immune response in the lamina propria of the intestinal wall (Glick, 1978). Thus far, the colonization mechanism of $S$. enteritidis in the immune organs is not clear and further studies are required to understand the same.

Salmonella cells have to attach to or form a close association with the intestinal epithelium in order to colonize the gut and sub-sequently invade the underlying tissues. Previous studies suggested that $S$. enteritidis cells were removed through circulation in the lymphatic system, especially the Peyer's patches in the gut (Takata et al., 2003). In the studies, the spleens were positive at $10 \mathrm{~h}$ PI but not the blood. This indicates that the $S$. enteritidis cells may have been removed through circulation in the lymphatic system primarily and this finding is similar to the results obtained in previous researches (Deng et al., 2008b).

Moreover, recent studies have shown that the systemic spread of Salmonella can occur to some extent without removal through the lymphatic system and blood circulation (Vasquez-Torres et al., 2000). Pathogens presented subepithelially or even luminally by dendritic cells or CD18-expressing phagocytes can be transferred directly to the liver and spleen (Sierro et al., 2001).

Previous studies showed that there is an association between Salmonella infection and intracellular survival of the organism in macrophages which can be regarded as safe sites for bacterial multiplication (Dunlap et al., 1991). The mechanism underlying the survival of $S$. enteritidis within macrophages is unclear and it seems likely that the type 3 secretion system encoded by Salmonella pathogenicity island two may play a major role in this survival (Hensel et al., 1998).

One of the functions of the Salmonella pathogenicity island 2 is to inhibit NADPH oxidase-dependent killing of Salmonella (Vasquez-Torres et al., 2000). Furthermore, it has been reported that the $S$. typhimurium genome encodes many genes responsible for resistance against the stressful environment encountered within the macrophage. Such stress includes the production of superoxide anions $\left(\mathrm{O}_{2}^{-}\right)$and other Reactive Oxygen Species (ROS) by NADPH oxidase and production of NO and other Reactive Nitrogen Species (RNS) by inducible Nitric Oxide (NO) synthase (iNOS) (Gilberthorpe et al., 2007). A number of important bacterial pathogens infect, replicate and persist within nucleated cells of the host and $\mathrm{T}$ cell-mediated immunity has proven to be a critical factor in the effective clearance of many such intracellular bacterial pathogens. Moreover, Salmonella can induce the suppression of cellular responses (Zhang et al., 2000). Simultaneously, it has been reported that chicken macrophages display differences in their responses to $S$. enteritidis and $S$. typhimurium and contribute to the differential pathogenesis of these Salmonella serovars (Bihl et al., 2003). Further, it has been reported that $S$. enteritidis infection induces less inflammation resulting in a more commensal environment in the host while an S. typhimurium infection can be cleared more rapidly by induction of inflammatory molecules (Okamura et al., 2005). S. enteritidis produced an increase in splenic CD3 and reduced $B$ populations, it was difficult to associate this increase with $S$. enteritidis clearance due to lack of any significant changes in $\mathrm{CD}^{+}$or $\mathrm{CD}^{+}$cells (Mittrucker et al., 2002). The functions of the spleen in filtration, immune responsiveness and activation of 
complement have been well documented. The spleen is made up of a lymphocyte-rich white pulp and macrophage-rich red pulp it is comprised of distinctive $B$ cells and macrophages. Therefore, what researchers described above may be the reason for why a significant number of $S$. enteritidis cells can be tested in the spleen in this study.

Over the 12 days period, the $S$. enteritidis populations in the jejunum and ileum were higher (by 10-100 times) than those in other regions of the gut. It has been reported that the differences in the lymphoid tissue (especially Peyer's patches), villi, mucosal layer and the ganglioside GM3 and neutral glycolipids in various regions of the gut may be important factors influencing $S$. enteritidis invasion (Carter and Collins, 1974). Further, it has been reported that in chickens, $S$. enteritidis has an unusual tendency to alter the heterogeneity of the LPS O-chain and the fimbriae of S. enteritidis have high affinity for the vaginal epithelium (De Buck et al., 2004a, b). The present study indicate that different regions of the gut differ in their susceptibility to $S$. enteritidis colonization and invasion. Thus far, the mechanism of colonization by $S$. enteritidis in the gut is not clear and requires further studies.

In the previous study, a same type of investigation have been performed in duck, chicken, pigeon and mouse after oral challenge by a real-time PCR assay (Deng et al., 2008a; He et al., 2010, 2011a, b). The results of these researches were similar to the results obtained in the present study. $S$. enteritidis DNA was consistently detected in all the samples. The copy number of $S$. enteritidis DNA in each tissue reached a peak at 24-36 $\mathrm{h}$ PI with the ileum, jejunum and spleen containing high concentrations of $S$. enteritidis cells.

\section{CONCLUSION}

In this study will help in understanding the pathogenesis of $S$. enteritidis infection in vivo and may help in the development of a live Salmonella vaccine in future.

\section{ACKNOWLEDGEMENT}

The research was supported by Science and Technology Agency of Guizhou Province, No. 2010 (2262).

\section{REFERENCES}

Akaki, C., M. Shimazu, T. Baba, S. Tsuji, H. Kodama, M. Mukamoto and T. Kajikawa, 1997. Possible migration of harderian gland immunoglobulin a bearing lymphocytes into the caecal tonsil in chickens. J. Vet. Med. Ser. B, 44: 199-206.
Bihl, F., L. Salez, M. Beaubier, D. Torres and L. Lariviere et al., 2003. Overexpression of tolllike receptor 4 amplifies the host response to lipopolysaccharide and provides a survival advantage in transgenic mice. J. Immunol., 170: 6141-6150.

Carter, P.B. and F.M. Collins, 1974. The route of enteric infection in normal mice. J. Exp. Med., 139: 1189-1203.

Cooper, M.D., 2002. Exploring lymphocyte differentiation pathways. Immunol. Rev., 185: 175-185.

De Buck, J., F. Pasmans, F. van Immerseel, F. Haesebrouck and R. Ducatelle, 2004a. Tubular glands of the isthmus are the predominant colonization site of Salmonella enteritidis in the upper oviduct of laying hens. Poult. Sci., 83: 352-358.

De Buck, J., F. van Immerseel, F. Haesebrouck and R. Ducatelle, 2004b. Effect of type 1 fimbriae of Salmonella enterica serotype Enteritidis on bacteraemia and reproductive tract infection in laying hens. Avian Path., 33: 314-320.

Deng, S.X., A.C. Cheng, M.S. Wang and P. Cao, 2008a. Serovar-specific real-time quantitative detection of Salmonella enteritidis in the gastrointestinal tract of ducks after oral challenge. Avian Dis., 52: 88-93.

Deng, S.X., A.C. Cheng, M.S. Wang, B. Yan and N.C. Yin, $2008 \mathrm{~b}$. A study of the distribution patterns and levels of Salmonella enteritidis in the immune organs of ducklings after oral challenge by serovar-specific real-time PCR. Avian Dis., 52: 507-512.

Dibb-Fuller, M.P., E. Allen-Vercoe, C.J. Thorns and M.J. Woodward, 1999. Fimbriae- and flagellamediated association with and invasion of cultured epithelial cells by Salmonella enteritidis. Microbiology, 145: 1023-1031.

Dunlap, N.E., W.H. Jr. Beniamin, R.D. Jr. McCall, A.B. Tilden and D.E. Briles, 1991. A safe site for Salmonella typhimurium is within splenic cells during the early phase of infection in mice. Microb. Pathogenesis, 10: 297-310.

Gast, R.K. and C.W. Beard, 1990. Serological detection of experimental Salmonella enteritidis infections in laying hens. Avian Dis., 34: 721-728.

Gilberthorpe, N.J., M.E. Lee, T.M. Stevanin, R.C. Read and R.K. Poole, 2007. NsrR: A key regulator circumventing Salmonella enterica serovar Typhimurium oxidative and nitrosative stress in vitro and in IFN--stimulated J774.2 macrophages. Microbiology, 153: 1756-1771.

Gillespie, I.A., S.J. Brien, G.K. Adak, L.R. Ward and H.R. Smith, 2005. Foodborne general outbreaks of Salmonella enteritidis phage type 4 infection, Englang and Wales, 1992-2002: Where are the risks? Epidemiol. Infect., 133: 795-801. 
Glick, B., 1978. The immune response in the chicken: Lymphoid development of the bursa of fabricius and thymus and an immune response role for the gland of harder. Poult. Sci., 57: 1441-1444.

Glick, B., 1995. Embryogenesis of the bursa of Fabricius: Stem cell, microenvironment and receptor-paracrine pathways. Poult. Sci., 74: 419-426.

He, G.Z., W.Y. Tian, N. Qian, A.C. Cheng and S.X. Deng, 2010. Quantitative studies of the distribution pattern for Salmonella enteritidis in the internal organs of chicken after oral challenge by a real-time PCR. Vet. Res. Commun., 34: 669-676.

He, G.Z., W.Y. Tian, N. Qian and S.X. Deng, 2011a. The pathogenesis of Salmonella enterica serovar enteritidis in subcutaneously infected pigeon: A quantitative time-course study using real-time PCR. J. Anim. Vet. Adv., 10: 909-913.

He, G.Z., W.Y. Tian, N. Qian and S.X. Deng, $2011 \mathrm{~b}$. Populations of Salmonella enteritidis in the tissues of reproductive organs in laying hens after oral challenge: A real-time PCR study. J. Anim. Vet. Adv., 8: 945-948.

Hensel, M., J.E. Shea, S.R. Waterman, R. Mundy and T. Nikolaus et al., 1998. Genes encoding putative effector proteins of the type III secretion system of Salmonella pathogenicity island 2 are required for bacterial virulence and proliferation in macrophages. Mol. Microbiol., 30: 163-174.

Li, W., S. Watarai, T. Iwasaki and H. Kodama, 2004. Suppression of Salmonella enterica serovar Enteritidis excretion by intraocular vaccination with fimbriae proteins incorporated in liposomes. Dev. Comp. Immunol., 28: 29-38.

Mittrucker, H.W., A. Kohler and S.H. Kaufmann, 2002. Characterization of the murine T-lymphocyte response to Salmonella enterica serovar Typhimurium infection. Infect. Immun., 70: 199-203.
Okamura, M., H.S. Lillehoj, R.B. Raybourne, U.S. Babu and R.A. Heckert et al., 2005. Differential responses of macrophages to Salmonella enterica serovars Enteritidis and Typhimurium. Vet. Immunol. Immunpathol., 107: 327-335.

Sayegh, C.E. and M.J. Ratcliffe, 2000. Perinatal deletion of $B$ cells expressing surface Ig molecules that lack V(D)Jencoded determinants in the bursa of Fabricius is not due to intrafollicular competition. J. Immunol., 164: $5041-5048$.

Scott, T.R., 2004. Our current understanding of humoral immunity of poultry. Poult. Sci., 83: 574-579.

Sierro, F., B. Dubois, A. Coste, D. Kaiserlian, J.P. Kraehenbuhl and J.C. Sirard, 2001. Flagellin stimulation of intestinal epithelial cells triggers CCL20-mediated migration of dendritic cells. Proc. Natl. Acad. Sci. USA., 98: 13722-13727.

Takata, T., J. Liang, H, Nakano and Y. Yoshimura, 2003. Invasion of Salmonella enteritidis in the tissues of reproductive organs in laying Japanese quail: An immunocytochemical study. Poult. Sci., 82: 1170-1173.

Vasquez-Torres, A., Y. Xu, J. Jones-Carson, D.W. Holden and S.M. Lucia et al., 2000. Salmonella pathogenicity island 2-dependent evasion of the phagocyte NADPH oxidase. Science, 287: 1655-1658.

Weill, J.C. and C.A. Reynaud, 1987. The chicken B cell compartment. Science, 238: 1094-1098.

Yan, B., A.C. Cheng, M.S. Wang, S.X. Deng and Z.H. Zhang et al., 2008. Application of an indirect immunofluorescent staining method for detection Salmonella enteritidis in paraffin slices and antigen location in infected duck tissues. World J. Gastroenterol., 14: 776-781.

Zhang, X.L., I.S. Tsui, C.M. Yip, A.W. Fung and D.K. Wong et al., 2000. Salmonella enterica serovar Typhi uses type IVB pili to enter human intestinal epithelial cells. Infect. Immunol., 68: 3067-3073. 